\title{
Using Nursery Rhymes to Foster Phonological and Musical Processing Skills in Kindergarteners
}

\author{
Jonathan Bolduc ${ }^{1,2}$, Pascal Lefebvre ${ }^{3}$ \\ ${ }^{1}$ Faculty of Education, University of Ottawa, Ottawa, Canada \\ ${ }^{2}$ Faculty of Music, Université Laval, Quebec City, Canada \\ ${ }^{3}$ School of Rehabilitation Sciences, Faculty of Health Sciences, University of Ottawa, Ottawa, Canada \\ Email: jonathan.bolduc@uottawa.ca
}

Received May $9^{\text {th }}, 2012$; revised June $10^{\text {th }}, 2012$; accepted June $27^{\text {th }}, 2012$

\begin{abstract}
The aim of this study was to assess the efficiency of four learning conditions to develop phonological and musical processing skills through a set of 10 nursery rhymes. According to the analysis of the teachers' practices, eight kindergarten classes ( $\mathrm{n}=100$ kindergarteners) were paired and assigned to one of the following conditions: 1) music; 2) language; 3) combined [music and language]; and 4) passive listening (control classes). Participants in conditions 1,2, and 3 were met for 40 minutes per week over a ten-week period. In condition 1, the nursery rhymes were supplemented by musical activities and in condition 2 by language activities. Condition 3 was a combination of activities from conditions 1 and 2. In condition 4, children listened to a recording of the same nursery rhymes for 15 minutes daily during free exploration periods. No intervention was proposed for this control condition. All participants were evaluated using the same phonological and musical processing measures prior to and after the implementation of the program. Results indicated that children in conditions 1, 2 and 3 significantly improved their phonological awareness and their invented spelling skills at post-test. However, only the two conditions in which the music component was integrated enhanced significantly their results at the verbal memory task. Children in conditions 1, 3 and 4 enhanced tonal and rhythm perception skills. This study demonstrated that supplementing nursery rhymes with language activities is an efficient manner to develop emergent literacy skills, but the addition of musical activities could also boost phonological processing skills.
\end{abstract}

Keywords: Kindergarten; Nursery Rhymes; Phonological Awareness; Invented Spelling; Memory; Tonal Perception; Rhythm Perception; Emergent Literacy; Music Education

\section{Introduction}

Research has shown that nursery rhymes, songs and listening activities can help preschoolers take the first steps towards becoming competent readers (Cunningham, 1991 in Danielson, 2000; Goswami, 2001; Raz \& Bryant, 1990). It has been suggested that phonological and musical processing skills are related (Rubinson, 2009). Few researchers have compared the effects of music and language interventions offered to four and five-year-old children. Some studies have indicated that musical conditions enhance phonemic awareness (Gromko, 2005), vocabulary (Galacia, Gomez, \& Flores, 2006; Register, 2001; Standley \& Hughes, 1997), word recognition (Bolduc, 2009; Fetzer, 1994) and invented spelling abilities (Bolduc, 2009). In an effort to fill in the gaps of previous findings, this study examines which learning conditions 1) music; 2) language; 3) combined [music and language] and 4) passive listening) seem to develop phonological and musical processing skills most efficiently. For this purpose, a program based on nursery rhymes was used among French-speaking kindergarteners. The findings offer information relevant to pedagogical decisions and support complementary literacy initiatives in schools.

\section{Phonological Processing Skills}

The term phonological processing skills refers to the mental operations that rely on the abstract representation of sound units of language (Lonigan, 2006; Troia, 2004). According to a metaanalysis conducted by the National Early Reading Panel (2008), three of these skills, when measured in preschoolers, show a unique variance in the prediction of reading success in primary grades: phonological access to lexical store, phonological memory, and phonological awareness. Phonological access to lexical store enables efficient retrieval of phonologically coded information from long-term memory (Wagner \& Torgesen, 1987). It is often measured by rapid-naming tasks in which children are asked to name an array of familiar pictures as quickly as possible. Phonological memory is a component of the working memory dedicated to the phonologically-based coding of verbal information (Baddeley, 1986). To measure it, children are usually asked to repeat verbal material such as letters, numbers or non-words. Phonological awareness refers to the sensitivity to sound units of oral language such as syllables, rhyme and phonemes, and the ability to manipulate them mentally (Gillon, 2004). It can be measured through numerous tasks such as rhyme detection, syllable deletion, phonemic segmentation, etc. More precisely, a deeper phonological awareness at the phoneme level (phonemic awareness) is most predictive of reading success (Ehri et al., 2001). However, shallower levels such as rhyme awareness would also seem to contribute to learning of reading (Kirtley, Bryant, MacLean \& Bradley, 1989).

The contributing role of phonological processing skills in 
emergent literacy cannot be explained without the involvement of letter knowledge. Also identified as one of the best predictors of reading success (National Early Reading Panel, 2008), letter knowledge refers to the child's ability to identify and name the letters from the alphabet of their language. A reciprocal relationship has been established between phonological processing and letter knowledge development in preschoolers (Burgess \& Lonigan, 1998). In fact, learning letters facilitates the development of phonemic awareness, and higher-level phonological processing skills promote the improvement of letter knowledge. Progressively, the child also becomes aware of the unique relationship between spoken language units and letters: the alphabetic principle (Adams, 1990). The mastery of the alphabetic principle implies learning the bidirectional correspondence between sounds and letters. Early decoding and spelling in primary grades (the beginning of formal instruction) finally brings together phonological processing skills, alphabet knowledge, and the mastery of the alphabetic principle (Ehri \& Roberts, 2006). The decoding of words requires the sounding out of letters (the alphabetic principle), and the holding of the evoked sounds in working memory (phonological memory) in order to blend them (phonemic awareness) to form a word that can be spoken (phonological access to lexicon). Early spelling requires evoking a word (phonological access to lexicon), segmenting it into individual sounds (phonemic awareness), and converting these into letters (alphabetic principle) in the correct sequence (phonological memory).

Even though most of the research concerning phonological processing skills focused on English, these skills have also been shown to be critical in other alphabetic languages such as French (e.g., Demont \& Gombert, 1986; Ecalle \& Magnan, 2007). However, phonological awareness development differs from language to language because it is influenced by the phonetic properties of the language the child is learning (Gombert, 1992). Thus, English developmental data on phonological awareness cannot be directly transferred to French. Duncan, Colé, Seymour \& Magnan (2006) have shown that phonological awareness development in English-speaking and Frenchspeaking children from four to six years of age followed distinct developmental trajectories. Syllable awareness was more accessible prior to formal literacy instruction for Frenchspeaking preschoolers than for their English-speaking counterparts; phoneme and rhyme awareness tended to emerge with formal reading and writing instruction in primary school in French kindergarteners. Other studies have confirmed the precedence of syllable awareness in French (Bruck, Genesee \& Caravolas, 1997; Courcy, Béland \& Pitchford, 2000; Ecalle \& Magnan, 2002, 2007; Lefebvre, Girard, Desrosiers, Trudeau, \& Sutton, 2008). It would seem, in French, rhyme units are not as noticeable as in English for preschoolers (Goswami, 1999). This developmental difference has to be taken into account when planning phonological awareness activities for French kindergarteners.

\section{Musical Processing Skills}

As with phonological processing skills, musical processing skills involve mental operations that help identify, compare, distinguish and reproduce pitch, duration, intensity and timbre of a variety of sound stimuli (Sloboda, 2005). Research has shown that these four parameters have a significant impact on musical development during early childhood (Trehub, 2004,
2006). Pitch refers to sound frequency. In preschool, emphasis should be laid on identification of very contrasting sounds (high-pitched versus low-pitched) because children have difficulty recognising minute nuances. Judgement is greatly influenced by listening context (Sloboda, 2005; Zimmerman, 1971). By the end of Kindergarten, most children are able to distinguish and reproduce melodies containing three to five sounds (Trehub, 2006). Duration represents the temporal value of music (rhythm). According to studies carried out with preschool children, children show a marked preference for quicker tempi (Colwell \& Richardson, 2002). As with pitch, moderate tempi are difficult to identify for young children. Depending on listening conditions, these will be classified as slow or fast (Temmerman, 2000). Intensity describes musical nuances, or sound volume. In this area as well, children oscillate between extremes (loud/soft), and have difficulty identifying moderate intensities (Flohr, 2003). Timbre, often called sound quality, refers to the distinctive tone quality differentiating one instrument from another. Children usually have no difficulty recognizing and distinguishing instrument sounds from age four on (Campbell \& Scott-Kassner, 2002). Auditory discrimination tasks, in which children are asked to compare sound sequences (pitch, duration, intensity, and timbre) and determine if they are similar or different, remain the most used measures of musical skills (Bentley, 1966; Gordon, 1979, 1984).

Research suggests that music may stimulate cognitive abilities, such as auditory perception, in early childhood. Correlational studies have shown that children between the ages of four and eight who score higher in pitch and duration processing tests also obtain higher scores in some phonological awareness tasks, such as syllable detection, syllable segmentation, phonemic segmentation and rhyme detection (Anvari, Trainor, Woodside, \& Levy, 2002; Bolduc \& Montésinos-Gelet, 2005; Lamb \& Gregory, 1993; Peynircioglu, Durgunoglu, \& Oney-Kusefoglu, 2002; Rubinson, 2009). Quasi-experimental studies have suggested that music training may promote the development of memory for sound and metacognitive knowledge, three components also involved in the development of language (Bolduc, 2009; Franklin, Moore, Yip, \& Jonides, 2008; Trainor, Shahin \& Roberts, 2003). Musical training focuses children's attention on elements that are different, but potentially important in the emergence and development of linguistic skills.

Research has shown that children are particularly attentive to the sounds around them during early childhood (Temmerman, 2000). According to Gordon $(1999,2003)$ this period is the optimal time to nurture and develop musical knowledge because innate musical potential seems to stabilize before the first year of primary school. Studies have also shown that the learning environment has a direct impact on the development of musical abilities. Depending on their home environment and the education they receive, children achieve varying levels of perceptive and productive abilities (Colwell \& Richardson, 2002). Between the ages of three and six, certain children achieve a basic level of ability, characterized by global listening without analysis, while others develop finer listening and analysis skills and manage to distinguish musical parameters more precisely (Corrigall \& Trainor, 2010). Time allocated to music in a school setting should thus be considered. Indeed some associations, such as Music Educators National Conference [MENC] (1995), specify that at least 20 minutes per day should be dedicated to music in Kindergarten. Ideally, many short activities are carried out throughout the day. 


\section{Nursery Rhymes, Phonological and Musical Processing Skills}

The impact of nursery rhymes on phonological processing skills has been explored in a few studies. Fernandez-Fein and Baker (1997) showed that English-speaking preschoolers exposed to nursery rhymes in their environment tend to perform better on rhyme and syllable tasks. Similarly, Pullen and Justice (2003) provided examples of explicit instructions relating to rhyme and syllable awareness added to nursery rhymes. According to these researchers, adding an explicit element to an engaging, meaningful and enjoyable activity such as reciting nursery rhymes would better aid the phonological development of preschoolers who are more at risk of developing reading and writing difficulties in elementary school. Other research has supported this hypothesis (Flett \& Conderman, 2002; Justice \& Kaderavek, 2004; Williams \& Rask, 2003). Moreover, Bryant, Bradley, Maclean and Crossland (1989) and MacLean, Bryant and Bradley (1987) have established that English-speaking children's knowledge of nursery rhymes at the age of three can predict rhyme awareness at the age of four. In turn, this could predict phonemic awareness, as well as reading and spelling performance at the age of five. Other studies carried out with foreign-language learners have highlighted the effectiveness of nursery rhymes in emergent literacy development (Qing-Feng, 2007). Despite this fact, we don't know much about Frenchspeaking children (Gauthier \& Lejeune, 2008). This population needs to be investigated further. As we mentioned earlier, phonological awareness development differs from language to language and English developmental data cannot be directly transferred to French (Gombert, 1992).

Nursery rhymes may similarly enhance musical processing skills. Some studies have demonstrated that nursery rhymes improve understanding of musical structures, and help children distinguish and recognize binary (march) and ternary (lullaby, waltz) measures (Hargreaves, 1986; Radocy \& Boyle, 2003). Duration seems to be the most important musical parameter involved in nursery rhymes (Bryant and al., 1989; Gauthier \& Lejeune, 2008; Williams \& Rask, 2003). It has been argued that rhythm is also closely related to linguistic structure and could improve word segmentation (Rubinson, 2009; Douglas \& Willats, 1994; Moritz, 2007). However, other musical parameters could also be involved. As a learning game, nursery rhymes provide opportunities to initiate children to pitch, intensity and timbre. Educators have suggested that nursery rhymes are a good way to introduce low/high and soft/loud concepts, and intonation in early childhood settings (Campbell \& Scott- Kassner, 2002; McDonald \& Simons, 1989). The scientific literature, however, does not provide further insight. More research is needed to determine the impact of nursery rhymes on musical processing skills.

\section{The Current Study}

Based on a nursery rhyme program, the current study has set out to examine which learning conditions 1) music; 2) language; 3) combined [music and language] and 4) passive listening) seem to develop phonological and musical processing skills most efficiently among French-speaking kindergarteners. Based on the literature, if auditory processing and memory for sound undergird task performance in music and phonological awareness, then the combined condition (3) will build auditory proc- essing ability and extends memory for sound, which, in turn, will cause significant gains in phonological awareness.

\section{Method}

\section{Participants}

This study involved eight kindergarten classes of four to six year-olds in a single public elementary school. Each class was comprised of 13 to 20 children of varied ethnic backgrounds. All kindergarteners participated in the activities, but data was collected only with those for whom parental authorizations were obtained ( $n=51$ girls and 49 boys). According to socioeconomic data for on the school population, $34 \%$ of children come from low-income families. Less than $4 \%$ are monitored for behavioral, integration or learning difficulties.

\section{Procedures}

Three experimental conditions and one control condition were formed. To ensure the greatest possible homogeneity, classes were paired following analysis of the teachers' emergent literacy practices (metalinguistic awareness, concepts about print, pre-reading, pre-writing), and musical practices (listening activities, signing, composing) (Bolduc, 2009; Montésinos-Gelet, Besse, Armand \& Morra, 3003). Logistics, as well as the school administrators' need to keep classes intact, prevented random assignment. Table 1 shows assignment of kindergarteners to the four learning conditions of this study: music (experimental classes, condition 1); language (experimental classes, condition 2); combined [music and language] (experimental classes, condition 3); and passive listening (control classes, condition 4).

\section{Instruction}

Each experimental class participated in a total of 10 sessions: 40 minutes once per week over a ten-week period (January to April 2011). The condition 1 program was offered by an early childhood music specialist, and the condition 2 program, by a speech language pathologist. Both specialists led the condition 3 program. Generalist teachers attended each session to assist the specialists. No specialist was involved in condition 4 .

In every session, each experimental class learned a new nursery rhyme (from a set of 10 nursery rhymes). Musical structures alternated from binary (march style) to ternary (lullaby style). Each nursery rhyme contained known monosyllabic and polysyllabic words of varying syllabic structure (vowel-consonant; consonant-vowel; consonant-consonant-vowel; consonant-vowelconsonant), words starting with the same initial phoneme, rhymes, as well as two pseudo words: the name of an invented character and an invented verb.

Table 1.

Distribution of children in conditions.

\begin{tabular}{cccccc}
\hline Learning Conditions & $N$ & Girls & Boys & $\begin{array}{c}\text { X } \\
\text { (Month) }\end{array}$ & $\begin{array}{c}\text { S.D. } \\
\text { (Month) }\end{array}$ \\
\hline C1 (Music) & 22 & 13 & 9 & 59 & 3 \\
C2 (Language) & 26 & 13 & 13 & 57 & 2 \\
C3 (Music and Language) & 28 & 14 & 14 & 59 & 3 \\
C4 (Passive Listening) & 24 & 11 & 13 & 59 & 4 \\
\hline
\end{tabular}


The first 10 minutes of each session were the same for all the experimental classes. The nursery rhyme was recited to the pupils, known and invented words were identified, and the text was learned using illustrations. The following 30 minutes varied according to condition. In condition 1 (music), nursery rhyme was supplemented by varying pitch, setting it to known melodies, inventing melodies, playing rhythm games, varying sound intensity, and accompanying it with different melodic and non melodic instruments. In condition 2 (language), the nursery rhyme was matched with simple and complex phonological tasks linked with syllable, rhyme, and phonemic awareness. Condition 3 (combined [music and language]) involved a combination of complemented activities from conditions 1 and 2; musical activities and phonological tasks took 15 minutes each. Finally, no targeted session was offered for condition 4 (passive listening). Participants assigned to this condition listened to a recording of each nursery rhyme for 15 minutes during free exploration periods daily (one new nursery rhyme per week). No further activities were offered.

\section{Testing}

Prior to and following implementation of the experimental and control conditions, all the children were evaluated using the Phonological awareness measure [PAM] (Armand \& Montésinos-Gelet, 2001), the Invented spelling measure [ISM] (Morin \& Montésinos-Gelet, 2003), one verbal memory task taken from the Nouvelles épreuves d'évaluation du langage [N-EEL; New Tests for Language Evaluation] (Chevrié-Muller \& Plaza, 2001), and the Primary measures of music audition [PMMA] (Gordon, 1979). All measures were administered individually, except the PMMA, which was performed in a group setting. One task (triangle) taken from the Kaufman assessement battery for children [K-ABC] (Kaufman \& Kaufman, 1993) was used to measure the cognitive equivalence of the participants amongst the groups at pretest.

The PAM by Armand and Montésinos-Gelet (2001) was developed for preschoolers. Children were presented with: 1) a non-sequential syllable identification task; 2) a non-initial sequential syllable identification task; 3) a rhyme identification task; 4) an initial phoneme identification task; 5) an initial phoneme categorization task; and 6) an initial phoneme suppression task. A computer was used to administer each task.

The ISM (Morin \& Montésinos-Gelet, 2003) was completed by all participants since phonological awareness involves graphical components as well as auditory discrimination. Children were asked to write three words in French (chapeau [hat], cerise [cherry], avion [plane]), chosen for their structural characteristics, without using a model (transcribing, copying). They had to guess the spelling of the words based on their prior knowledge.

The verbal task from the N-EEL (Chevrié-Muller \& Plaza, 2001) was used to evaluate participants' short-term sequential memory (digit span). Children had to repeat, in order, a series of three to five numbers given by the examiner.

Musical aptitudes were evaluated with Gordon's measure (1979). The PMMA consisted of one tonal and one rhythmic measure. In both of them, participants had to compare two recorded sound sequences and decide whether they were identical or not. On the answer sheet, a picture represented each item heard. If both sequences were alike, pupils circled the pair of identical faces, but if they were different, they circled the pair of contrasting faces.

The triangle task taken from the K-ABC (Kaufman \& Kaufman, 1993) was used to assess cognitive abilities. Children had up to two minutes to reproduce abstract models by arranging several identical triangles (blue on one side, yellow on the other) in specific patterns.

Testing was conducted following procedures specified in the manual for each measure. Testing sessions lasted about two 25minute periods per child, and were carried out during school hours on site. Training programs began two weeks following the end of the pretesting. Post-test occurred two weeks after the experimental and control conditions. Graduate students blind to the experimental conditions and hypotheses performed all testing.

\section{Scoring}

\section{Phonological Awareness Measure}

Each of the six tasks includes four assessment items for 24 possible correct answers. Results of the six tasks are considered as a whole. As a measure of internal consistency, Cronbach's alpha has been established at .66 . $^{1}$

\section{Invented Spelling Measure}

Each word is marked based on the number of extracted phonemes and of combined syllables as well as exclusive use of letters in the word. Seven points can be given for the word chapeau [hat], eight for the word cerise [cherry], and six for the word avion [plane], for a maximum of 21 correct answers. Results of the three words are treated together. The reliability coefficient of the ISM (Morin \& Montésinos-Gelet, 2003) has never been provided.

\section{Nouvelles épreuves d'évaluation du langage}

The verbal memory task includes nine evaluation items worth one point each. The standardised mark varies from one to five with for an average mark of three. Mark is determined using the global result and the precise age of each child. The reliability coefficient of the N-EEL (Chevrié-Muller \& Plaza, 2001) is .76.

\section{Primary Measures of Music Audiation}

Tonal and rhythmic measures are comprised of 40 evaluation items each. One point is given for each correct answer. Results from each measure are treated separately. The reliability coefficient of the PMMA (Gordon, 1979) is .85 for the tonal and .86 for the rhythmic measure.

\section{Kaufman Assessment Battery for Children: K-ABC}

The triangle task is comprised of 15 evaluation items. One point is given per correct answer. The standardised mark is determined using the global result for the task and the precise age of each child. It can vary from one to 19 , for an average mark of 10. The mean reliability coefficient of the K-ABC (Kaufman \& Kaufman, 1993) is .90 for preschool children.

\section{Date Analysis Procedure}

Data analysis procedure was performed utilizing the Statistics Package for the Social Sciences (SPSS) 17.0 software. Non-parametric analyses statistics were realized with consid-

${ }^{1}$ Reliability coefficients between .65 and .75 are considered good, and those between .75 and .90 are deemed excellent. 
eration the limited number of participants in each condition $(<$ 28). Moreover, the normal distribution of the data in each condition could not be assured for all measures. Kruskal Wallis Tests were used on all pre and post-test measures in order to compare the scores in the four conditions and evaluate their equivalence. If significant differences were noticed, a post-hoc comparison using the Mann-Whitney U Test was performed. Wilcoxon matched-pair Signed-rank Tests were used to check for significant differences between pre and post-test measures. Cohen's measures were performed to determine the effect size of significant changes. For adjusting the statistical results for multiples comparisons, an alpha level of .01 was established.

\section{Results}

Table 2 shows medians on all measures. No significant difference was noticed at pretest (phonological awareness: $X^{2}(3, n$ $=100)=.83, p=.843$; invented spelling: $X^{2}(3, n=100)=.54$, $p=.910$; verbal memory: $X^{2}(3, n=96)=2.25, p=.522$; tonal: $X^{2}(3, n=99)=1.10, p=.777$; rhythm: $X^{2}(3, n=99)=2.26, p$ $=.520$; triangles: $\left.X^{2}(3, n=99)=6.51, p=.089\right)$. This result indicates the equivalence across the four conditions before the interventions.

Important improvements were observed on the phonological awareness measure in three conditions. Using Cohen (1988) criteria, large effect sizes $(>.50)$ were noted for the music, combined and language conditions after the interventions. However, the magnitude effect of the first two conditions was greater compared to the third one (music: $z=-4.12, p<.001, r=.62$; combined $z=-4.65, p<.001, r=.62$; language: $z=-3.71, p$ $<.001, r=.51)$. No contrast was seen in the passive listening condition $(z=-2.31, p=.021)$. A significant difference in this measure was found across the four conditions at post-test, $X^{2}(3$, $n=100)=11.44, p=.01)$. Post-hoc comparisons demonstrated that the music, combined and language conditions scores were higher then the ones the passive listening condition.

Participants in all conditions enhanced their results on the invented spelling measure at post-test. A large effect size was observed in the music condition $(z=-3.52, p<.001, r=.54)$. Medium to large effects $(>.30-.49)$ were noticed in the passive listening $(z=-3.17, p=.002, r=.45)$, combined $(z=-3.00, p$ $=.003, r=.40)$, and language $(z=-2.75, p=.006, r=.38)$ conditions. No significant difference was established for this measure across the four conditions following the interventions, $\left.X^{2}(3, n=98)=1.32, p=.72\right)$.

In the two conditions in which the music component was integrated, results in the verbal memory task improved significantly. Large effect sizes were observed for the music $(z=$
$-4.23, p<.001, r=.64)$ and the combined $(z=-4.16, p<.001$, $r=.56)$ conditions. No difference was noted for the language $(z$ $=-1.11, p=.070)$ and the passive listening $(z=-2.23, p=.026)$ conditions after the interventions. A difference in this measure emerged across the four conditions at post-test, $X^{2}(3, n=96)=$ $14.71, p=.002)$. Post-hoc comparisons showed a difference between the music and the language conditions.

Similar results were obtained on the tonal measure. Improvements and large effect sizes were noticed in music $(z=$ $-3.49, p<.001, r=.53)$ and combined $(z=-3.85, p<.001, r$ $=.53)$ conditions. No contrast was found for the language $(z=$ $-1.18, p=.238)$ and the passive listening $(z=-1.25, p=.210)$ conditions. No significant difference was demonstrated for this measure across the four conditions following the interventions, $\left.X^{2}(3, n=99)=5.64, p=.130\right)$.

Improvements were also noticed in the rhythm measure in three conditions. Large effect size was established in the passive listening condition $(z=-3.89, p<.001, r=.56)$. Medium to large effects were observed for the music $(z=-2.92, p$ $=.003, r=.44)$ and combined $(z=-2.84, p=.004, r=.39)$ conditions. No difference was noted for the language condition $(z=-1.39, p=.166)$. No significant difference was shown for this measure across the four conditions following the interventions, $\left.X^{2}(3, n=99)=6.86, p=.076\right)$.

\section{Discussion}

The current study implemented a nursery rhymes program among 100 French-speaking kindergarteners from eight kindergarten classes of a single public elementary school. The purpose of this project was to assess the efficiency of four learning conditions to develop phonological and musical processing skills. It was predicted that the combined condition would have a more significant impact than the others (i.e. the music, language and passive listening conditions). The results partially supported this hypothesis.

Regarding the phonological processing skills, various results were obtained for phonological awareness, invented spelling and verbal memory. Across the four conditions, only children in the music and combined conditions significantly improved their skills across all three measures. In accordance with previous research (Bolduc, 2009; Franklin, Moore, Yip, \& Jonides, 2008; Trainor, Shahin, \& Roberts, 2003), music training should be an efficient approach to enhance auditory perception in early childhood. It seems that some musical activities, such as discrimination tasks, could boost phonological processing skills in a more general manner. In the present study, children in the language condition also improved their results considerably in

Table 2.

Medians on all measures for the four conditions.

\begin{tabular}{|c|c|c|c|c|c|c|c|c|c|c|c|c|}
\hline \multirow{2}{*}{ Learning Conditions } & \multirow[t]{2}{*}{$N$} & \multicolumn{2}{|c|}{ PAM } & \multicolumn{2}{|c|}{ ISM } & \multicolumn{2}{|c|}{$\begin{array}{c}\text { N-EEL } \\
\text { Auditivo-memory }\end{array}$} & \multicolumn{2}{|c|}{$\begin{array}{l}\text { PMMA } \\
\text { Tonal }\end{array}$} & \multicolumn{2}{|c|}{$\begin{array}{l}\text { PMMA } \\
\text { Rhythm }\end{array}$} & \multirow{2}{*}{$\begin{array}{c}\text { K-ABC } \\
\text { Triangles } \\
\text { Pre }\end{array}$} \\
\hline & & Pre & Post & Pre & Post & Pre & Post & Pre & Post & Pre & Post & \\
\hline C1 (Music) & 22 & 11.5 & 17 & 7 & 7 & 4.5 & 7 & 12 & 15.5 & 10 & 14 & 9 \\
\hline C2 (Language) & 26 & 11.5 & 15 & 5 & 8 & 4 & 4 & 10.5 & 12 & 11 & 12 & 10 \\
\hline C3 (Music and Language) & 28 & 11 & 15 & 4 & 7.5 & 4 & 6 & 11 & 14 & 10 & 13 & 8 \\
\hline C4 (Passive listening) & 24 & 12 & 12.5 & 3.5 & 6 & 4 & 5 & 13 & 12 & 10 & 12 & 10 \\
\hline
\end{tabular}


the phonological awareness and invented spelling measures. It is well documented that early intervention programs in which the link between sounds and letters is explicitly stated allow preschoolers to master the alphabetic principle (Ehri et al., 2001; Gillon, 2004; National Early Reading Panel, 2008). Despite that, others factors, such as family literacy practices and teaching methods can positively influence young learners. Such external variables could help to explain some anecdotal results. This is the case for the children of the passive listening condition who got good scores at the invented spelling measure without having been involved in any music and/or language trainings.

Concerning the musical processing skills, only the children in the two conditions that involved music improved tonal and rhythm perception. Various activities targeting those two skills, such as tone identification and body percussion were carried out in those specific conditions every week. Children in the passive listening condition also improved rhythm perception. This result may be explained by the fact that they listened to nursery rhymes (with rhythm patterns and lyrics only) on daily basis. In the language condition, children did not show improvement in their musical processing skills, probably because they did not receive explicit musical training or day-to-day exposure to the nursery rhymes. However, the improvement observed in the children involved in the music, combined and passive listening conditions was not sufficient to consider their musical processing skills significantly superior of those in the language condition after the interventions.

\section{Limitations}

Although a great importance was given to internal and external validity in this research, it has some limitations. Firstly, this study was limited by the small sample $(N=100$ kindergarteners) from only one public elementary school. Future research with a larger sample population may produce more robust results. Longitudinal study is also recommended to explore associations between phonological and musical processing skills over time and their outcomes on music education and literacy. Secondly, the composition and dynamics of each class may have influenced the unfolding of the interventions. Because participants were assigned randomly, it was not possible to control for the proportion of children in each group with behavioral, integration or learning difficulties. Finally, the two conditions in which children showed the greatest improvements (music and combined) were those that were led by the music educator. In fact, an instructor effect may have biased the results. Treatment fidelity analysis was not carried out. Additionally, the music and combined conditions took place away from the school, at the university. The motivation of the children in those conditions who came every week to the Mus-Alpha Research Lab may have positively influenced the results. A John Henry effect could also explain the improvement observed among the participants in the passive listening condition at post-test.

\section{Implications and Future Research}

The current study supports the embedded-explicit model (Flett \& Conderman, 2002; Justice \& Kaderavek, 2004; Williams \& Rask, 2003) to enhance emergent literacy skills. The integration of explicit instructions in the music, combined and language conditions led to more powerful effects compared to the passive listening condition. In this regard, preschool teachers are encouraged to go beyond the recitation of nursery rhymes. They could instead envision nursery rhymes as a rich learning context. Adding language activities targeting phonological awareness, vocabulary and inference skills is a more effective manner to reach that objective. Complementing nursery rhymes, however, with musical activities seems yet more powerful. By favouring the development of music perception abilities we help children increase their phonological memory and acquire metaphonological abilities without relying exclusively on language activities.

Further research is needed to clarify the relationship between language and music in early childhood. To this point, no study has clearly established which musical processing skills are related to the phonological processing skills: more general auditory processing and cognitive skills might be intertwined. Additional research encompassing also these more general skills could be helpful for understanding the underlying processes in action during language and music interventions with kindergarteners. At some point, it would be interesting to reply this study with pupils in different daycare facilities or kindergartens. It would also be pertinent to look at the effects of a music and language interventions in first and second grades of primary school. Similarly, research with, as participants, children who have language developmental difficulties, such as dyslexia and dysorthographia may contribute significantly to the literature and help to improve educational practices.

\section{Acknowledgements}

This research was supported by external grants from the Social Sciences and Humanities Research Council of Canada and the Canadian Foundation of Innovation to Dr. Bolduc and by an internal grant from the University of Ottawa to Drs. Bolduc and Lefebvre. We thank all the administrators, teachers and parents whose interest and support made this work possible. Special thanks to the 100 preschoolers involved in this project. We are especially grateful to all undergraduate and graduate students for assistance in this research.

\section{REFERENCES}

Adams, M. J. (1990). Beginning to read: Thinking and learning about print. Cambridge, MA: MIT Press.

Anvari, S. H., Trainor, L. J., Woodside, J., \& Levy, B. A. (2002). Relation among musical skills, phonological processing and early reading ability in preschool children. Journal of Experimental Psychology, 83, 111-130.

Armand, F., \& Montésinos-Gelet, I. (2001). Apprentissage de la lecture et de l'écriture en milieux pluriethniques: Etudes des contextes langagiers et du degré d'automatisation des processus en lecture (Organisme subventionnaire: Immigration et métropoles). Créateur du logiciel: Michel Bastien.

Baddeley, A. (1986). Working memory. New York, NY: Oxford University Press.

Bentley, A. (1966). Musical ability in children and its measurement. London: Harrap.

Bolduc, J. (2009). Effects of a music programme on kindergartners' phonological awareness skills. International Journal of Music Education, 27, 37- 47. doi:10.1177/0255761408099063

Bolduc, J., \& Montésinos-Gelet, I. (2005). Pitch awareness and phonological awareness. Psychomusicology, 19, 3-14. doi: $10.1037 / \mathrm{h} 0094043$

Bruck, M., Genesee, F., \& Caravolas, M. (1997). A cross-linguistic study of early literacy acquisition. In B. A. Blachman (Ed.), Founda- 
tions of reading acquisition and dyslexia: Implications for early intervention (pp. 145-162). Mahwah, NJ: Erlbaum.

Bryant, P. E., Bradley, L. L., Maclean, M., \& Crossland, J. (1989). Nursery rhymes, phonological skills and reading. Journal of Child Language, 16, 171-184. doi:10.1017/S0305000900010485

Burgess, S. R., \& Lonigan, C. J. (1998). Bidirectional relations of phonological sensitivity and prereading abilities: Evidence from a preschool sample. Journal of Experimental Child Psychology, 26, 117141. doi:10.1006/jecp.1998.2450

Campbell, P. S., \& Scott-Kassner, C. (2002). Music in childhood: From preschool to the elementary grades (2nd ed.). New York, NY: Schirmer Books.

Chevrié-Muller, C., \& Plaza, M. (2001). Nouvelles épreuves pour l'examen du langage ( $N$-EEL). Paris: Éditions du centre de psychologie appliquée.

Cohen, J. W. (1988). Statistical power analysis for the behavior sciences (2nd ed.). Hillsdale, NJ: Lawrence Erlbaum Associates.

Colwell, R. \& Richardson, C. (2002). (Eds). The new handbook of research on music teaching and learning. New York, NY: Oxford University Press.

Corrigall, K. A., \& Trainor, L. J. (2010). Musical enculturation in preschool children: Acquisition of key and harmonic knowledge. Music Perception, 28, 195-200. doi:10.1525/mp.2010.28.2.195

Courcy, A., Béland, R., \& Pitchford, N. J. (2000). Phonological awareness in French-speaking children at risk for reading disabilities. Brain and Cognition, 43, 124-130.

Danielson, E. (2000). The importance of nursery rhymes. MF01/PC01 Plus Postage. Retrieved March 14, 2011, from Eric Database.

Demont, E., \& Gombert, J.-E. (1996). Phonological awareness as a predictor of recoding skills and syntactic awareness as a predictor of comprehension skills. British Journal of Educational Psychology, 66, 315-332. doi:10.1111/j.2044-8279.1996.tb01200.x

Douglas, S., \& Willats, P. (1994). The relationship between musical ability and literacy skills. Journal of Research in Reading, 17, 99107. doi:10.1111/j.1467-9817.1994.tb00057.x

Duncan, L. G., Colé, P., Seymour, P. H. K., \& Magnan, A. (2006). Differing sequences of metaphonological development in French and English. Journal of Child Language, 33, 369-399. doi:10.1017/S030500090600732X

Ecalle, J., \& Magnan, A. (2007). Development of phonological skills and learning to read in French. European Journal of Psychology of Education, 22, 153-167. doi:10.1007/BF03173519

Ecalle, J., \& Magnan, A. (2002). The development of epiphonological and metaphonological processing at the start of reading: A longitudinal study. European Journal of Psychology of Education, 17, 4762. doi:10.1007/BF03173204

Ehri, L. C., \& Roberts, T. (2006). The roots of learning to read and write: Acquisition of letters and phonemic awareness. In D. K. Dickinson, \& S. B. Neuman (Eds.), Handbook of early literacy research (Vol. 2; pp. 113-131). New York, NY: Guilford Press.

Ehri, L. C., Nunes, S. R., Willows, D. M., Schuster, B. V., YaghoubZadeh, Z., \& Shanahan, T. (2001). Phonemic awareness instruction helps children learn to read: Evidence from the national reading panel's meta-analysis, Reading Research Quarterly, 36, 250-287. doi:10.1598/RRQ.36.3.2

Fernandez-Fein, S., \& Baker, L. (1997). Rhyme and alliteration sensitivity and relevant experiences among preschoolers from diverse backgrounds. Journal of Literacy Research, 29, 433-459. doi:10.1080/10862969709547967

Fetzer, L. (1994). Facilitating print awareness and literacy development with familiar Children's song. Unpublished doctoral dissertation, Marshall, TX: East Texas University.

Flett, A., \& Conderman, G. (2002). 20 ways to promote phonemic awareness. Intervention in School and Clinic, 37, 242-245. doi: $10.1177 / 105345120203700409$

Flohr, J. W. (2003). Musical lives of young children. Upper Saddle River, VA: Prentice Hall.

Franklin, M., Moore, K., Yip, C., \& Jonides, J. (2008). The effects of musical training on verbal memory. Psychology of Music, 36, 353365. doi: $10.1177 / 0305735607086044$

Galicia, I. X., Gomez, I., \& Flores, M. T. (2006). Implementing a mu- sical program to promote preschool children's vocabulary development. Early Childhood Research and Practice, 8. URL (last checked 6 January 6 2011). http://ecrp.uiuc.edu/v8n1/galicia.html

Gauthier, J.-M., \& Lejeune, C. (2008). Nursery rhymes and their usefulness in the child's development. Neuropsychiatrie de l'enfance et de adolescence, 56, 413-421. doi:10.1016/j.neurenf.2008.04.009

Gillon, G. T. (2004). Phonological awareness: From research to practice. New York, NY: Guilford Press.

Gombert, J. E. (1992). Metalinguistic development. London, UK: Harvester Weatsheaf.

Gordon, E. E. (2003). A Music learning theory for newborn and young children (3rd ed). Chicago, IL: G.I.A. Publications.

Gordon, E. E. (1999). All about audiation and music aptitudes. Music Educator Journal, 86, 41-44. doi:10.2307/3399589

Gordon, E. E. (1984). Instrument timbre preference test. Chicago, IL: G.I.A. Publications.

Gordon, E. E. (1979). Primary measures of music audiation. Chicago, IL: G.I.A. Publications.

Goswami, U. (2001). Early phonological development and the acquisition of literacy. In D. K. Dickinson, \& S. B. Neuman (Eds.), Handbook of early literacy research (Vol. 1; pp. 111-125). New York, NY: Guilford Press.

Goswami, U. (1999). Causal connections in beginning reading: The importance of rhyme. Journal of Research in Reading, 22, 217-240. doi:10.1111/1467-9817.00087

Gromko, J.E. (2005). The effect of music instruction on phonemic awareness in beginning readers. Journal of Research in Music Education, 53, 199-209.

Hargreaves, D. J. (1986). The developmental psychology of music. Cambridge, MA: New York University press. doi: 10.1017/CBO9780511521225

Justice, L. M., \& Kaderavek, J. N. (2004). Embedded-explicit emergent literacy intervention I: Background and description of approach. Language Speech and Hearing Services in Schools, 35, 201-211. doi:10.1044/0161-1461(2004/020)

Kaufman, A. S., \& Kaufman, N. L. (1993). K-ABC, Assessment battery for children (French version). Paris: Éditions du Centre de Psychologie appliquée.

Kirtley, C., Bryant, P., MacLean, M., \& Bradley, L. (1989). Rhyme, rime, and the onset of reading. Journal of Experimental Child Psychology, 48, 224-245. doi:10.1016/0022-0965(89)90004-0

Lamb, S. J., \& Gregory, A. H. (1993). The relationship between music and reading in beginning readers. Educational Psychology, 13, 1927. doi: $10.1080 / 0144341930130103$

Lefebvre, P., Girard, C., Desrosiers, K., Trudeau, N., \& Sutton, A. (2008). Phonological awareness tasks for French-speaking preschoolers. Canadian Journal of Speech-Language Pathology and Audiology, 32, 158-168.

Lonigan, C. J. (2006). Conceptualizing phonological processing skills in prereaders. In D. K. Dickinson, \& S. B. Neuman (Eds.), Handbook of early literacy research (Vol. 2; pp. 77-89). New York, NY: Guilford Press.

MacLean, M., Bryant, P., \& Bradley, L. (1987). Rhymes, nursery rhymes, and reading in early childhood. Merrill-Palmer Quarterly, 33, 255-281.

McDonald, D. T., \& Simons, G. (1989). Musical growth and development: Birth through six. New York, NY: Schirmer Books

Montésinos-Gelet, I., Besse, J.-M., Armand, F., \& Morra, V. (2003). Declared practices of emergent literacy in France and in Quebec. The AIMTE International Conference, Lisbon.

Morin, M.-F., \& Montésinos-Gelet, I. (2003). Les commentaires métagraphiques en situation collaborative d'écriture chez des enfants de maternelle. Archives de Psychologie, 70, 41-66.

Moritz, C. E. (2007). Relationship between phonological awareness and music rhytmic subskills in kindergarten children and comparaison of subskills in two schools with different amounts of music instruction. Unpublished Master's Thesis, Medford, MA: Tufts University.

National Association for Music Education (1995). Prekindergarten music education standards: Guidelines for early-childhood educators, music specialists, parents, and day-care providers. Reston, MA: 
National Association for Music Education.

National Early Literacy Panel (2008). Developing early literacy. Report of the National Early Literacy Panel: A Scientific synthesis of early literacy development and implication for intervention. National Institute for Literacy and National Center for Family Literacy, Jessup: Ed Pubs.

Peynircioglu, Z. F., Durgunoglu, A. Y., \& Oney-Kusefoglu, B. (2002). Phonological awareness and musical aptitude. Journal of Research in Reading, 25, 68-80. doi:10.1111/1467-9817.00159

Pullen, P. C., \& Justice, L. M. (2003). Enhancing phonological awareness, print awareness, and oral language skills in preschool children. Intervention in School and Clinic, 39, 87-98. doi:10.1177/10534512030390020401

Qing-Feng, L. (2007). Developing language skills through nursery rhymes. US-China Foreign Language, 5, 30-33.

Radocy, R. E., \& Boyle, J. D. (2003). Psychological foundation of music behavior (4e ed.). Springfield, VA: Charles C. Thomas.

Raz, I. T., \& Bryant, P. (1990). Social background, phonological awareness and children's reading. British Journal of Developmental Psychology, 8, 209-225. doi:10.1111/j.2044-835X.1990.tb00837.x

Register, D. (2001). The effects of an early intervention music curriculum on prereading/writing. Journal of Music Therapy, 38, 239-248.

Rubinson, L. E. (2009). A correlational study of the relationships between music aptitude and phonemic awareness of kindergarten children. Unpublished Doctoral Dissertation, Minneapolis, MN: Capella University.

Sloboda, J. A. (2005). Exploring the musical mind. London, UK: Oxford University Press.

Standley, J. M., \& Hughes, J. E. (1997). Evaluation of an early intervention music curriculum for enhancing prereading/writing skills.
Music Therapy Perspectives, 15, 79-85.

Temmerman, N. (2000). An investigation of the music activity preferences of preschool children. British Journal of Music Education, 17, 51-60. doi:10.1017/S0265051700000140

Trainor, L. J., Shahin, A., \& Roberts, L. E. (2003). Effects of musical training on auditory cortex in children. In G. Avanzini, C. Faienze, D. Miciacchi, L. Lopez, \& M. Majno (Eds.), The neurosciences and music: Mutual interactions and implications of developmental functions (pp. 506-513). New York, NY: Annals of the New York Academy of Sciences.

Trehub, S. E. (2006). Infants as musical connoisseurs. In G. McPherson (Ed.), The child as musician (pp. 33-49). Oxford: Oxford University Press. doi:10.1093/acprof:oso/9780198530329.003.0002

Trehub, S. E. (2004). Music in infancy. In J. Flohr (Ed.), Musical lives of young children. Englewood Cliffs, NJ: Prentice Hall.

Troia, G. A. (2004). Phonological processing and its influence on literacy learning. In C. A. Stone, E. R. Silliman, B. J. Ehren, \& K. Apel. (Eds.), Handbook of language and literacy: Development and disorders (pp. 271-301). New York, NY: Guilford Press.

Wagner, R. K., \& Torgessen, J. K. (1987). The natural of phonological processing and its causal role in the acquisition of reading skills. Psychological Bulletin, 101, 192-212. doi:10.1037/0033-2909.101.2.192

Williams, M., \& Rask, H. (2003). Literacy through play: How families with able children support their literacy development. Early Child Development and Care, 173, 527-533. doi:10.1080/0300443032000088276

Zimmerman, M. P. (1971). Musical characteristics of children. Reston, MA: National Association for Music Education. 